Received: $\quad 2015.08 .01$

Accepted: $\quad 2016.05 .20$

Published: 2016.11.07
Material/Methods:

Results:

Conclusions:

Keywords:

\section{Prothymosin-alpha and Ki-67 expression in pituitary adenomas*}

\section{Ekspresja protymozyny alfa i Ki-67 w gruczolakach przysadki}

\author{
Iga Wierzbicka-Tutka ${ }^{1, B, C, D, E, F}$, Grzegorz Sokołowski ${ }^{2, D}$, Agata Bałdys-Waligórska ${ }^{2, E}$, \\ Dariusz Adamek ${ }^{3, B}$, Edyta Radwańska ${ }^{3, B}$, Filip Gołkowski ${ }^{2, A, D, E, F, G}$ \\ 'Department of Gastroenterology, Hepatology and Infectious Diseases, Jagiellonian University Medical College, \\ Cracow, Poland \\ ${ }^{2}$ Department of Endocrinology, Jagiellonian University Medical College, Cracow, Poland \\ ${ }^{3}$ Department of Pathology, Jagiellonian University Medical College, Cracow, Poland
}

\section{Summary}

Introduction:

Prothymosin alpha (PTMA), a nuclear oncoprotein involved in cell cycle regulation, is used as a prognostic marker in many cancers. The histopathology of pituitary carcinomas and locally invasive adenomas is indistinguishable from that of benign tumors. A new marker is needed to differentiate these lesions. We evaluated PTMA in pituitary adenomas to determine its usefulness as a prognostic factor of tumor proliferation.

We conducted a retrospective analysis of a group of 27 patients, including 15 females (56\%) and 12 males (44\%) with a mean age of $58.6 \pm 12$ years, who underwent pituitary tumor surgery between 2003 and 2012. The Ki-67 and PTMA-nuclear (PTMA-n) and PTMA-cytoplasmic (PTMA-c) indices were determined by immunohistochemical staining. We studied histopathological features, clinical symptoms, and magnetic resonance imaging or computed tomography performed before surgery and one year following surgery to evaluate tumor size and progression.

The expression of Ki- 67 was revealed in $77.8 \%$ of adenomas, PTMA- $\mathrm{n}$ in $81.5 \%$ and PTMA-c in 92.6\%. The mean value of the Ki-67 index was 1.8\%, PTMA-n was $1.84 \%$, and PTMA-c was $35.6 \%$. There was a significant positive correlation between Ki-67 and PTMA- $n(p=0.009)$. We did not find any correlation between Ki-67, PTMA-c, and tumor progression. PTMA-n was found to be correlated with tumor size $(\mathrm{p}=0.045)$ and was higher in the case of gonadotropinomas $(\mathrm{p}=0.026)$.

The positive nuclear expression of Ki-67 and PTMA was observed in the majority of pituitary adenomas. Neither the expression of Ki-67 nor that of PTMA-c was related to tumor recurrence or local invasion.

pituitary adenoma $\cdot \mathrm{Ki}-67 \cdot \mathrm{PTMA} \cdot$ prothymosin alpha 


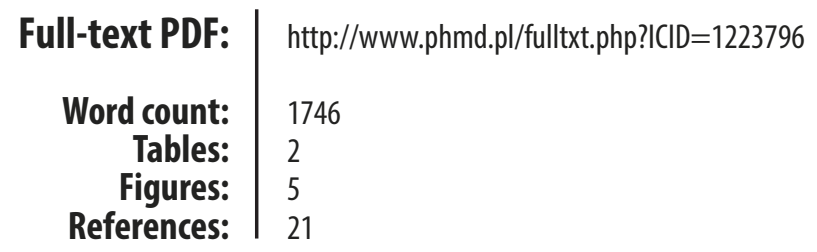

Author's address: Iga Wierzbicka-Tutka, MD, Department of Gastroenterology and Hepatology and Infectious Diseases, Jagiellonian University Medical College, 5 Śniadeckich Street, 31-501 Cracow, Poland; e-mail: igawierzbicka@gmail.com, tel.: 1242473 40, fax: 124247380

\begin{abstract}
Abbreviations: $\quad$ ACTH - adrenocorticotropic hormone; AIP - aryl-hydrocarbon receptor-interacting protein; BCl-2 - B-cell lymphoma 2; COX-2 - cyclooxygenase-2; CT - computed tomography; FPA - functioning pituitary adenoma; FSH - follicle-stimulating hormone; G1 - Gap 1 phase; G2 - Gap 2 phase; GH - growth hormone; Ki-67 - Ki-67 protein; LH - luteinizing hormone; $\mathbf{M}$ - mitosis; MIB-1 - monoclonal antibodies; MRI - magnetic resonance imaging; NCA - null cell adenoma; NFPA - non-functioning pituitary adenoma; PRL - prolactin; PTMA - prothymosin alpha; PTMA-c - prothymosin alpha-cytoplasmic; PTMA-n - prothymosin alpha-nuclear; PTTG - pituitary tumor transforming gene; $\mathbf{S}$ - synthesis; TSH - thyroid-stimulating hormone; VEGF - vascular endothelial growth factor; WHO - World Health Organization.
\end{abstract}

\section{INTRODUCTION}

In the majority of cases of benign adenomas, pituitary tumors are very rare (0.02\% of the population) [14]. They are divided by size into microadenomas $(<1 \mathrm{~cm})$ and macroadenomas $(\geq 1 \mathrm{~cm})[14]$.

According to the 2004 WHO classification, pituitary adenomas are typical, atypical, and cancerous $[14,16]$. Elevated invasiveness, mitotic index, nuclear staining for p53, and Ki-67 labeling index $>3 \%$ suggest aggressive behavior [19]. However, brain invasion is not accepted as the only criterion.

Clinical symptoms such as hormonal activity or symptoms associated with the "mass effect" and the invasion of surrounding tissues (supra-sellar extension, sinus cavernous invasion, and optic chiasm compression) may occur [3]. Many pituitary adenomas (3.7-20\%) are incidentally detected by computed tomography (CT) or magnetic resonance imaging (MRI) performed for unrelated reasons; they are also incidentally detected in about $10 \%$ of postmortem examinations [14].

Based on physical examinations and blood hormone levels, pituitary tumors can be divided into functioning (FPA) and non-functioning (NFPA) [14]. The predicted hormonal activity of a tumor is not always confirmed by postoperative immunohistological examination. According to the histopathological expression of specific pituitary hormones, adenomas are divided into the Pit-1 family (prolactinoma, PRL secretion: 50\%; somatotropinoma, GH secretion: $15-20 \%$; thyrotropinoma, TSH secretion: 1\%; plurihormonal adenoma), ACTH family (corticotropinoma: 5-10\%), gonadotropin family (gonadotropinoma, LH, FSH secretion: 1\%) and unclassified adenomas (hormone negative/null cell adenomas, NCA (30\%) and unusual plurihormonal adenomas) $[1,3,10]$.

Pituitary carcinomas (0.1-0.2\% of all cases of pituitary tumors) are diagnosed if metastasis is observed; their prognosis is very poor $[14,19]$. Therapy for large invasive tumors with post-surgery re-growth, persistent hormonal function despite near total resection, or pituitary carcinomas is challenging and includes, besides surgery and pharmacological treatment, radiotherapy and temozolomide [10]. In these cases, adjusted therapy and proper periodic monitoring are crucial.

Pituitary adenomas classified according to WHO guidelines do not always correlate with clinical prognoses [19]. Many are invasive (30-45\%), and some are clinically aggressive [19]. The WHO 2004 classification of pituitary adenomas does not include the term invasive and non-invasive adenoma. This aspect of the WHO classification has been criticized many times, and a need for the reexamination of the criteria of malignancy was reported $[1,10,19,21]$. Therefore, some authors divide adenomas into particular groups: non-invasive, non-invasive and proliferative, invasive +/- proliferative, and metastatic $[8,19]$. Some have suggested naming atypical adenomas carcinoma in situ or premetastatic cancer [11].

There are no defined histological criteria dividing benign and malignant tumors, and especially for distinguishing atypical adenoma from pituitary adenocarcinoma. Mar- 
kers are needed that can consistently correlate with biological tumor behavior. Such potential indicators of tumor behavior are markers of proliferation and angiogenesis. Besides the documented Ki-67 (MIB-1 antibody), topoisomerase II alpha, COX-2, and Bcl-2 were studied $[16,18]$. However, they have not yet shown consistent correlation with tumor invasiveness or recurrence [1]. PPTG (pituitary tumor transforming gene), VEGF, prothymosin alpha (PTMA), and AIP are new promising biological tumor behavior markers.

Ki-67 is a nuclear antigen expressed in phase G1, S, G2, and $\mathrm{M}$ of the cell cycle and recognized by the commercially available antibody MIB-1 $[2,7]$. The Ki-67 labeling indices can vary from $<1 \%$ to $23 \%$ in a series [15]. PTMA is an oncoprotein that is a product of the $2 \mathrm{q} 37.1$ gene and is present in nuclei or cytoplasm. It is involved in proliferation and protection against apoptosis; its overexpression has been found in cancers of the head and neck, lungs, kidney, bladder, and breast $[4,6,19]$.

The aim of this study was to:

- determine the usefulness of PTMA as a prognostic factor of the recurrence of pituitary adenoma;

- evaluate the relationship between the proliferative activity of pituitary adenomas, quantified by Ki-67 and PTMA indices, and their aggressive biology and clinical data;

- investigate the correlation between the PTMA labeling index and tumor size and local invasion.

\section{Material AND Methods}

Our study was a retrospective analysis of the clinical records and histopathological and immunohistochemical preparations of the pituitary adenomas of 27 patients of the Clinical Department of Endocrinology at the University Hospital in Cracow who underwent a transsphenoidal resection of the pituitary adenoma and/or craniotomy in the Clinical Department of Neurosurgery at the University Hospital in Cracow between 2003 and 2012. The diagnosis was established by clinical, biochemical, and radiological findings and was confirmed by surgery and a histopathological survey.

MRI or CT was performed before surgery and one year after surgery for all patients to determine potential tumor progression. Tumor size, defined as its largest dimension, and relation to neighboring tissues (sella turcica destruction, penetration into sinus cavernous, optic chiasm compression, suprasellar propagation) were studied using MRI/CT. Tumor invasiveness was defined by radiological criteria $[5,20]$ and from the surgeon's description found in patients' medical records. Tumor progression was defined as evidence of recurrence or increase of the remnant tumor in MRI/CT after one year of observation following surgery.
The surgical specimens were routinely processed, fixed in neutral buffered formalin, embedded in paraffin, and slided. Sections were incubated, inter alia, in the primary mouse monoclonal antibody Ki-67 clone MIB-1 antibody (Dako, M7240, 1:25) in the case of Ki-67, and in the primary monoclonal rabbit antibody prothymosin alpha (Acris-Antibodies $\mathrm{GmbH}, 1: 1000$ ) in the case of prothymosin alpha. In all cases, an evaluation of the Ki-67 and PTMA labeling index of the surgical specimens was performed using the antibody. To confirm the specificity of the primary antibody, positive and negative control tests were performed following the manufacturers' instructions.

Ki67 and PTMA-stained sections were evaluated by manual counting using an optical microscope (Nikon Optishot-2). Ten fields were selected in regions with the highest concentration of positive nuclei and were examined at a high power magnification (400x). Each field comprised 700 to 3800 cells in relation to the cellularity of the tumor specimen. The Ki-67 and PTMA-n indices were defined as the percentage of positive stained nuclei, and PTMA-c was defined as the percentage of positive cytoplasm (see photos in figure $1 \mathrm{a}, 1 \mathrm{~b}, 1 \mathrm{c}$ ).

Statistical analysis was performed using the R statistical package. Analysis of variance, Student's t-test, Pearson's $r$ correlation, Wilcoxon text, and Spearman's rho correlation were performed.

\section{RESULTS}

The results of a retrospective and basic immunohistochemical analysis of the group are shown in Table 1.

The occurrence of hormone immunopositive expression was established in 17 (63\%) cases. In some adenomas, the expression of more than one hormone was found. All studied groups consisted of macroadenomas.

\section{KI-67, PTMA-N, AND PTMA-c}

Results concerning the expression of Ki-67, PTMA-n, and PTMA-c are shown in Table 2.

The PTMA-n expression correlated with Ki-67 ( $\mathrm{p}=0.009)$, as presented in Figure 2.

There was no significant difference between PTMA-n, PTMA-c, and Ki-67 based on age or gender.

\section{Progression}

Progression of the tumor within 12 months of the observation occurred in 6 cases (22\%). We did not find any significant difference between Ki-67 or PTMA-c indices and tumor progression ( $\mathrm{p}=0.8$ in both).

However, the mean PTMA-n expression was significantly lower in the subpopulation with a tumor that progressed 
Table 1. Patients characteristics $(n=27)$.

\begin{tabular}{|c|c|c|}
\hline \multirow{2}{*}{ General data } & Age [years]: mean/median (min.-max.) & $58.6 / 61(29-80)$ \\
\hline & Gender: Female/Male & $15(55.5 \%) / 12(44.5 \%)$ \\
\hline \multirow{5}{*}{ Imaging results } & Largest dimension of tumor [mm] & 45 \\
\hline & Minimal dimension of tumor [mm] & 10 \\
\hline & Microadenoma / Macroadenoma & $0(0 \%) / 27(100 \%)$ \\
\hline & Optic chiasm compression & $17(63 \%)$ \\
\hline & Local invasion of tumor & $25(92.6 \%)$ \\
\hline \multirow{7}{*}{$\begin{array}{l}\text { Final clinical classification } \\
\text { of pituitary adenomas } \\
\text { in patient group }\end{array}$} & Clinically non-functioning adenoma (NFPA) & $20(74 \%)$ \\
\hline & Prolactinoma & $2(7.4 \%)$ \\
\hline & Acromegaly & $5(18.5 \%)$ \\
\hline & Cushing disease & 0 \\
\hline & Ganadotropinoma & 0 \\
\hline & Thyrotropinoma & 0 \\
\hline & Silent-ACTH adenoma & 0 \\
\hline \multirow{10}{*}{ Immunohistochemical findings } & Null cell adenoma (NCA) & $10(37 \%)$ \\
\hline & Hormonal immunopositivity & $17(63 \%)$ \\
\hline & GH positive & $4(15 \%)$ \\
\hline & PRL positive & $4(15 \%)$ \\
\hline & ACTH positive & $3(11 \%)$ \\
\hline & TSH positive & $1(4 \%)$ \\
\hline & FSH positive & $5(18 \%)$ \\
\hline & LH positive & $10(37 \%)$ \\
\hline & Plurihormonality & $4(15 \%)$ \\
\hline & Histopathological features of malignancy* & $1(4 \%)$ \\
\hline $\begin{array}{c}\text { Clinical observation } \\
\text { after } 1 \text { year }\end{array}$ & Progression & $6(22 \%)$ \\
\hline
\end{tabular}

*Traditional histopathological features of malignancy, like nuclear polymorphism, presence of mitotic figures, high cellularity, cytological atypias, presence of necrosis might be an indicator of more aggressive behavior.

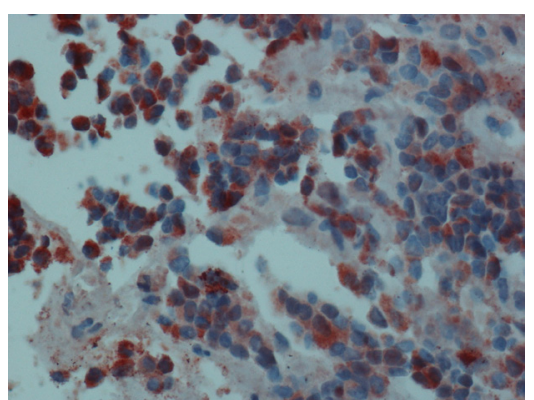

Fig. 1a. The strong, mainly cytoplasmatic, reaction to PTMA antibody, 400x magnification

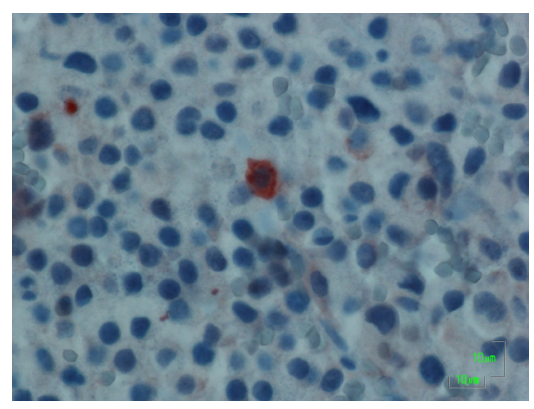

Fig. 1b. Strong immunopositive cytoplasmatic reaction to PTMA antibody in one cell, $600 \mathrm{x}$ magnification

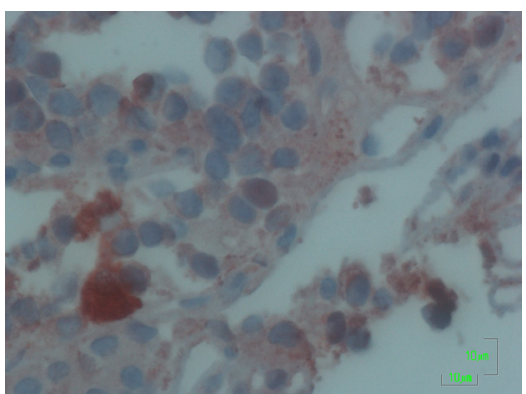

Fig. 1c. Several cells with mixed cytoplasmatic and nuclear reaction to PTMA antibody, $600 \mathrm{x}$ magnification 
Table 2. Expression of Ki-67 and PTMA in the group ( $n=27)$

\begin{tabular}{cccc}
\hline & Ki-67 & PTMA-c & PTMA-n \\
\hline frequency & $21 / 27(77.8 \%)$ & $25 / 27(92.6 \%)$ & $22 / 27(81.5 \%)$ \\
\hline medium $/$ median value [\%] & $1.8 / 1.4$ & $35.6 / 27.7$ & $1.84 / 0.67$ \\
\hline min.-max. [\%] & $0-5.71$ & $0-90.3$ & $0-9.04$ \\
\hline Correlation between Ki-67 / PTMA-c & & $\mathrm{p}=0.8$ & - \\
\hline Correlation between Ki-67 / PTMA-n & & - & $\mathrm{p}=0.009$ \\
\hline
\end{tabular}

PTMA-c: PTMA-cytoplasmatic, PTMA-n: PTMA-nuclear.

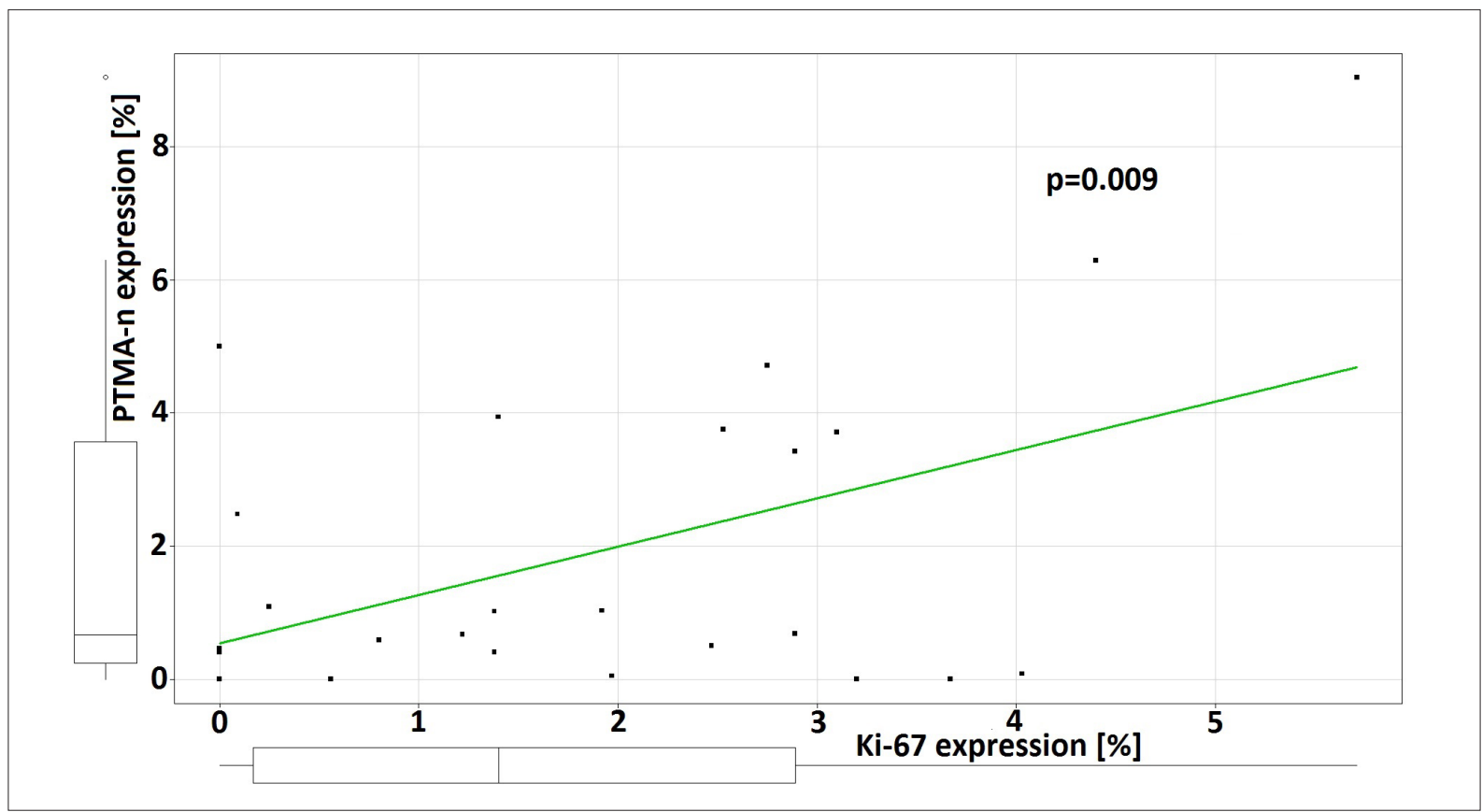

Fig. 2. Correlation between PTMA-n and Ki-67 expression

in comparison to the group with a tumor that did not progress $(0.94 \% \pm 0.32$ versus $2.1 \% \pm 0.97, p=0.046)$.

\section{LOCAL INVASION}

There was a statistically insignificant difference between studied markers and local tumor invasion and optic chiasm compression (in the case of PTMA-n, $p=0.06$; in PTMA-c, $\mathrm{p}=0.55$ ).

\section{HORMONAL ACTIVITY}

There was no significant difference between studied markers and clinical hormonal pituitary adenoma activity (FPA versus NFPA). Similarly, there was no significant difference between studied markers and general positive immunohistochemical hormonal expression (non-NCA versus NCA). However, in the group with gonadotropinoma, there was a significant difference. The PTMA-n median was significantly higher in the subpopulation with gonadotropinomas (positive immunohistochemical reaction to $\mathrm{FSH}$ and $\mathrm{LH}$ ) in comparison to the group without gonadotropinomas (3.095\%, [IQR=3.195] versus $0.45 \%$ [IQR=0.98], $\mathrm{p}=0.026$ ) (Figure 3).

Also, the PTMA-c median was significantly higher for the subpopulation with gonadotropinomas than in the group without gonadotropinomas (3.35\%, [IQR=42.86] versus $21.13 \%$, [IQR=24.9], $\mathrm{p}=0.039$ ) (Figure 4). There was no such difference in the case of Ki-67 ( $p=0.32)$.

\section{PTMA-N}

There was a significant correlation between PTMA-n and the size of the tumor $(p=0.045)$ (shown in Figure 5).

\section{Discussion}

Many studies aim to find a new biological marker that could be useful in the early diagnosis of pituitary adenomas or pituitary cancers. So far, a marker has not been found that can independently predict the aggressive behavior of tumors. A significant correlation between Ki-67 and the recurrence of tumors has been 


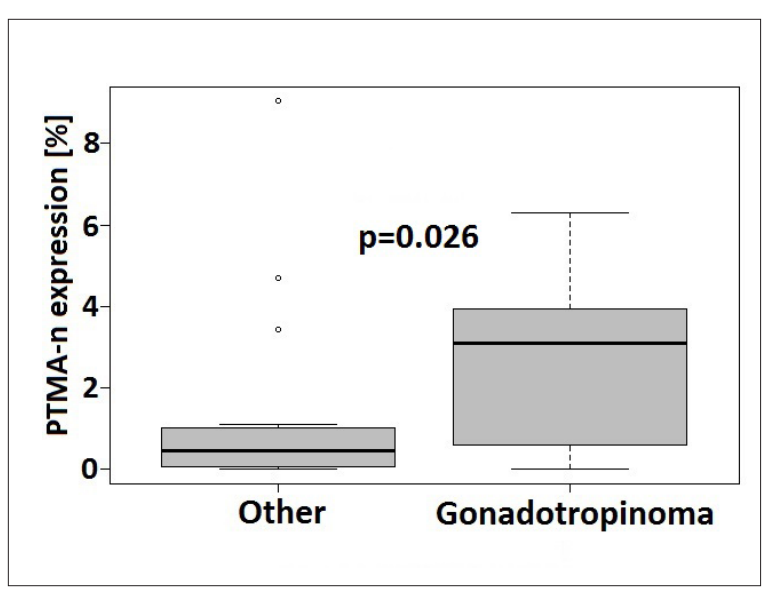

Fig. 3. Distribution of PTMA-n in patients with or without gonadotropinoma (Box plot)

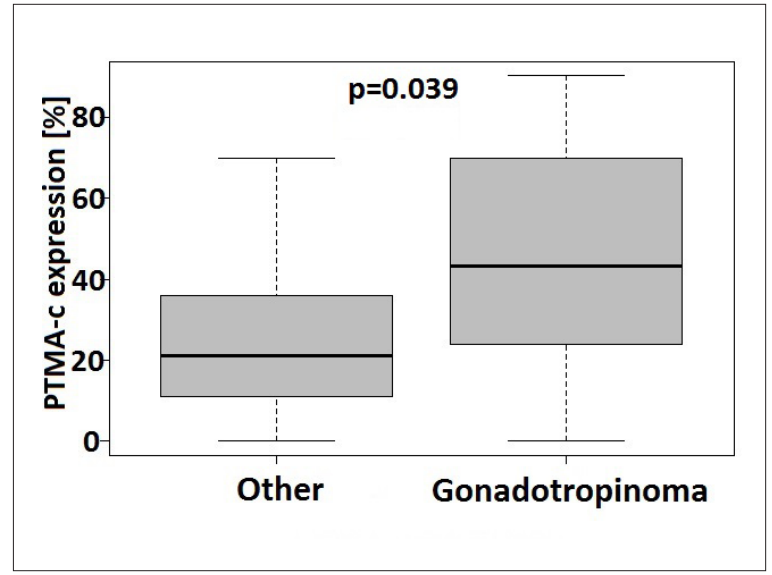

Fig. 4. Distribution of PTMA-c in patients with or without gonadotropinoma (Box plot)

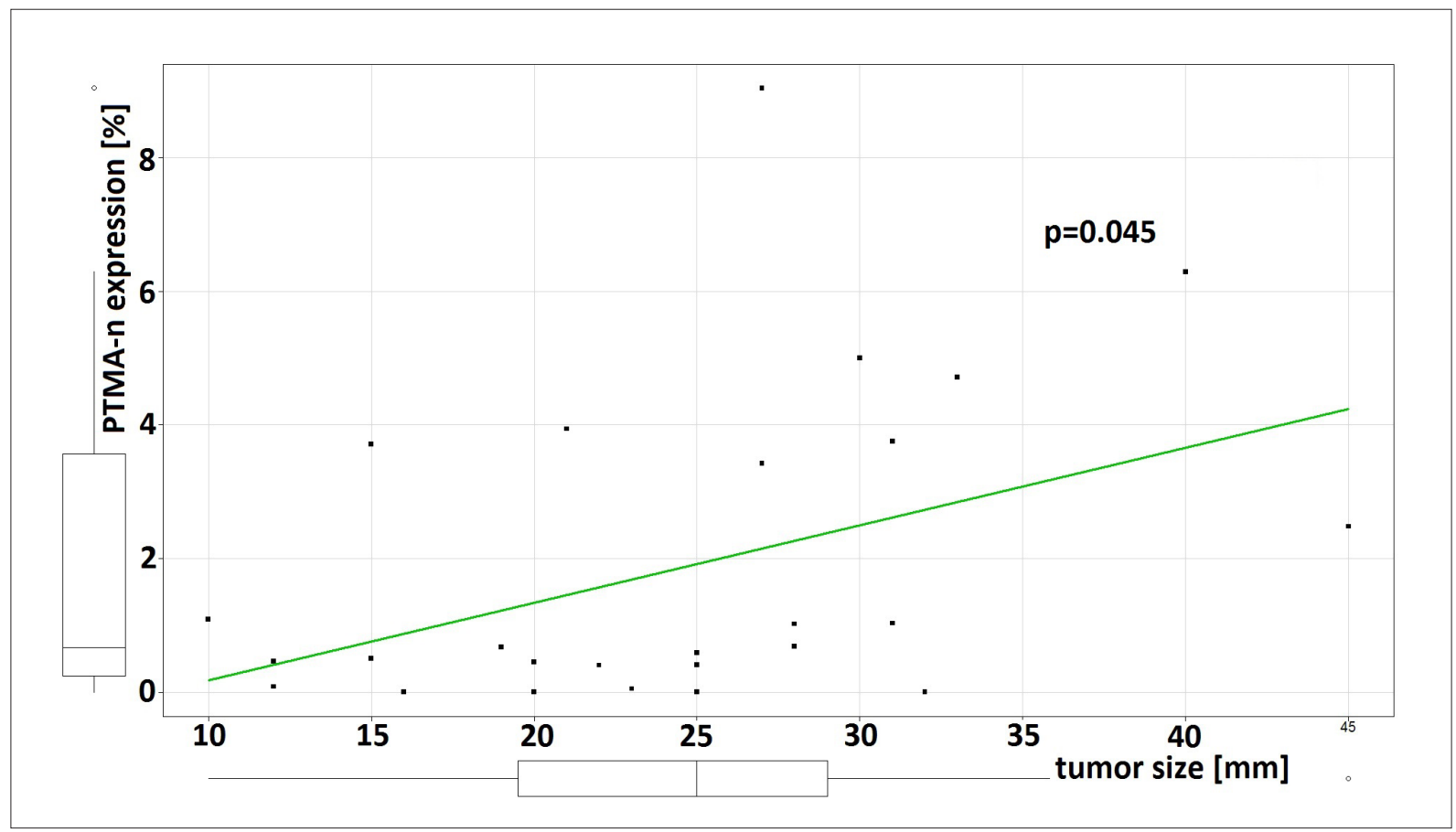

Fig. 5. Correlation between PTMA-n and size of tumor

found in several studies $[19,20,21]$. Some studies have shown a significant association between PTMA-n and the advanced stages of head and neck tumors and have revealed PTMA-n to be an independent predictor of poor prognosis $[14,17]$.

There have only been two studies of PTMA and pituitary adenoma; they were conducted by Pawlikowski et al., who studied the correlation between Ki-67 and PTMA and pituitary adenoma hormonal phenotype, proliferation, recurrence, and invasiveness [12,13].

According to the results of the second article and an analysis of 62 pituitary adenomas, the PTMA-n index was significantly higher in recurrent adenomas than in the primary tumors, and it was also higher in NFPA. No correlation between Ki-67 and PTMA or between PTMA and local invasion was found [13]. Strong immunostaining occurred not only in cell nuclei but also in the walls of intratumoral blood vessels; this also occurred in cytoplasm to a lesser degree [13].

As in our study, there was significantly higher mean expression of PTMA-n and PTMA-c in the group with gonadotropinomas.

However, our research did not confirm the role of PTMA as a marker of pituitary adenoma progression. In our study, tumor progression was defined as evidence of recurrence or increase of the remnant tumor in MRI/CT 
after one year of observation following surgery. We did not divide the analyzed group into primary and recurrent adenomas.

In contrast to the research of Pawlikowski, we found a significant correlation between Ki-67 and PTMA-n $(p=0.009)$ and between PTMA- $n$ and the size of the tumor $(\mathrm{p}=0.045)$.

The differences between the two studies may be the result of the difference between the size of the analyzed groups (62/27 patients) and the observation time of the studies (1 year/5 years).

\section{Conclusion}

The expression of Ki-67 and PTMA was observed in the majority of pituitary adenomas, and PTMA-n expression correlated with Ki-67. There was a significant correlation between PTMA-n and tumor size. PTMA-n and PTMA-c were significantly higher in gonadotropinomas than in other groups. However, the expression of neither Ki-67 nor PTMAc was related to tumor recurrence or local invasion.

Due to the discrepancies between previous studies, additional research is needed to reveal the role of PTMA in pituitary adenomas.

\section{RefERENCES}

[1] Al-Shraim M., Asa S.L.: The 2004 World Health organization classification of pituitary tumors: what is new? Acta Neuropathol., 2006; 111: 1-7

[2] Botelho C.H., Magalhães A.V., Mello P.A., Schmitt F.C., Casulari L.A.: Expression of p53, Ki-67 and c-erb B2 in growth hormone-and/ or prolactin-secreting pituitary adenomas. Arq. Neuropsiquiatr., 2006; 64: 60-66

[3] Dworakowska D., Grossman A.B.: The pathophysiology of pituitary adenomas. Best Pract. Res. Clin. Endocrinol. Metab., 2009; 23: $525-541$

[4] Karapetian R.N., Evstafieva A.G., Abaeva I.S., Chichkova N.V., Filonov G.S., Rubtsov Y.P., Sukhacheva E.A., Melnikov S.V., Schneider U., Wanker E.E., Vartapetian A.B.: Nuclear oncoprotein prothymosin $\alpha$ is a partner of Keap1: implications for expression of oxidative stressprotecting genes. Mol. Cell. Biol., 2005; 25: 1089-1099

[5] Knosp E., Steiner E., Kitz K., Matula C.: Pituitary adenomas with invasion of the cavernous sinus space: a magnetic resonance imaging classification compared with surgical findings. Neurosurgery, 1993; 33: 610-617

[6] Marek $Ł .:$ The role of the apoptosome in the activation of procaspase-9. Postępy Hig. Med. Dośw., 2013; 67: 54-64

[7] Mastronardi L., Guiducci A., Puzzilli F.: Lack of correlation between Ki-67 labelling index and tumor size of anterior pituitary adenomas. BMC Cancer, 2001; 1: 12

[8] Mete O., Ezzat S., Asa S.L.: Biomarkers of aggressive pituitary adenomas. J. Mol. Endocrinol., 2012; 49: R69-R78

[9] Oktar N.: Controversies and innovations in the new WHO classification of pituitary adenomas. J. Neurol. Sci. Turk., 2006; 23: 68-69

[10] Ortiz L.D., Syro L.V., Scheithauer B.W., Rotondo F., Uribe H., Fadul C.E., Horvath E., Kovacs K.: Temozolomide in aggressive pituitary adenomas and carcinomas. Clinics, 2012; 67 (Suppl. 1): 119-123

[11] Pasquel F.J., Vincenti C., Brat D.J., Oyesiku N.M., Ioachimescu A.G.: Pituitary carcinoma in situ. Endocr. Pract., 2013; 19: e69-e73

[12] Pawlikowski M., Radek M., Kunert-Radek J., Jaranowska M., Świętosławski J., Winczyk K.: Overexpression of prothymosin alpha is related to pituitary adenoma recurrence but not to adenoma invasiveness and proliferation. Endokrynol. Pol., 2014; 65: 382-386
[13] Pawlikowski M., Winczyk K.: Immunohistochemical detection of prothymosin alpha in pituitary adenomas - a new marker of tumor recurrence? Folia Histochem. Cytobiol., 2009; 47: 559-562

[14] Saeger W., Lüdecke D.K., Buchfelder M., Fahlbusch R., Quabbe H.J., Petersenn S.: Pathohistological classification of pituitary tumors: 10 years of experience with the German Pituitary Tumor Registry. Eur. J. Endocrinol., 2007; 156: 203-216

[15] Salehi F., Kovacs K., Scheithauer B.W., Lloyd R.V., Cusimano M.: Pituitary tumor-transforming gene in endocrine and other neoplasms: a review and update. Endocr. Relat. Cancer, 2008; 15: 721-743

[16] Sokołowski G., Bałdys-Waligórska A., Trofimiuk M., Adamek D., Hubalewska-Dydejczyk A., Gołkowski F.: Expression of cyclooxygenase-2 (COX-2) in pituitary tumours. Med. Sci. Monit., 2012; 18: CR252-CR259

[17] Tripathi S.C., Matta A., Kaur J., Grigull J., Chauhan S.S., Thakar A., Shukla N.K., Duggal R., Choudhary A.R., Dattagupta S., Sharma M.C., Ralhan R., Siu K.W.: Overexpression of prothymosin alpha predicts poor disease outcome in head and neck cancer. PLoS One, 2011; 6: e19213

[18] TrofimiukMüldner M., Bałdys-Waligórska A., Sokołowski G., Adamek D., Hubalewska-Dydejczyk A., Gołkowski F.: Topoisomerase II $\alpha$ as a prognostic factor in pituitary tumors. Pol. Arch. Med. Wewn., 2014; 124; 500-508

[19] Trouillas J., Roy P., Sturm N., Dantony E., Cortet-Rudelli C., Viennet G., Bonneville J.F., Assaker R., Auger C., Brue T., Cornelius A., Dufour H., Jouanneau E., François P., Galland F., et al.: A new prognostic clinicopathological classification of pituitary adenomas: a multicentric case-control study of 410 patients with 8 years post-operative follow-up. Acta Neuropathol., 2013; 126: 123-135

[20] Zada G., Lin N., Laws E.R.: Patterns of extrasellar extension in growth hormone-secreting and nonfunctional pituitary macroadenomas. Nerosurg. Focus, 2010; 29: 1-5

[21] Zada G., Woodmansee W.W., Ramkissoon S., Amadio J., Nose V., Laws E.R. Jr.: Atypical pituitary adenomas: incidence, clinical characteristics, and implications. J. Neurosurg., 2011; 114: 336-344

The authors have no potential conflicts of interest to declare. 